\title{
San Joaquin Valley blueberries evaluated for quality attributes
}

by Vanessa Bremer, Gayle Crisosto,

Richard Molinar, Manuel Jimenez,

Stephanie Dollahite and Carlos H. Crisosto

\section{Blueberry production in California} was estimated in 2007 at around 4,500 acres and is rapidly increasing. Common southern highbush cultivars with low chilling-hour requirements are being grown from Fresno County southward, including 'Misty', 'O'Neal', 'Emerald', 'Jewel', 'Star' and others. We characterized the quality parameters (soluble solids concentration, titratable acidity, ratio of soluble solids concentration to titratable acidity, firmness and antioxidant capacity) of six southern highbush blueberry cultivars grown at the UC Kearney Agricultural Center in Parlier, in the San Joaquin Valley, for three seasons (2005-2007). We also conducted in-store tests to evaluate their acceptance by consumers who eat fresh blueberries. We found that the southern blueberry cultivars currently grown under warm San Joaquin Valley conditions are producing blueberry fruit that is of acceptable quality to consumers and profitable to growers.

Tighbush blueberries (Vaccinium 1 corymbosum), native to the northeastern United States, are important commercial fruit (Jimenez et al. 2005) and are the most planted blueberry species in the world (Strik and Yarborough 2005). In the United States, blueberries traditionally have been grown in cooler northern regions; however, the development of new southern cultivars with low chilling-hour requirements (the accumulated number of hours below $45^{\circ} \mathrm{F}$ $\left[7.2^{\circ} \mathrm{C}\right]$ necessary to break dormancy) has made possible the expansion of blueberry production to the southern United States and California (Jimenez et al. 2005).

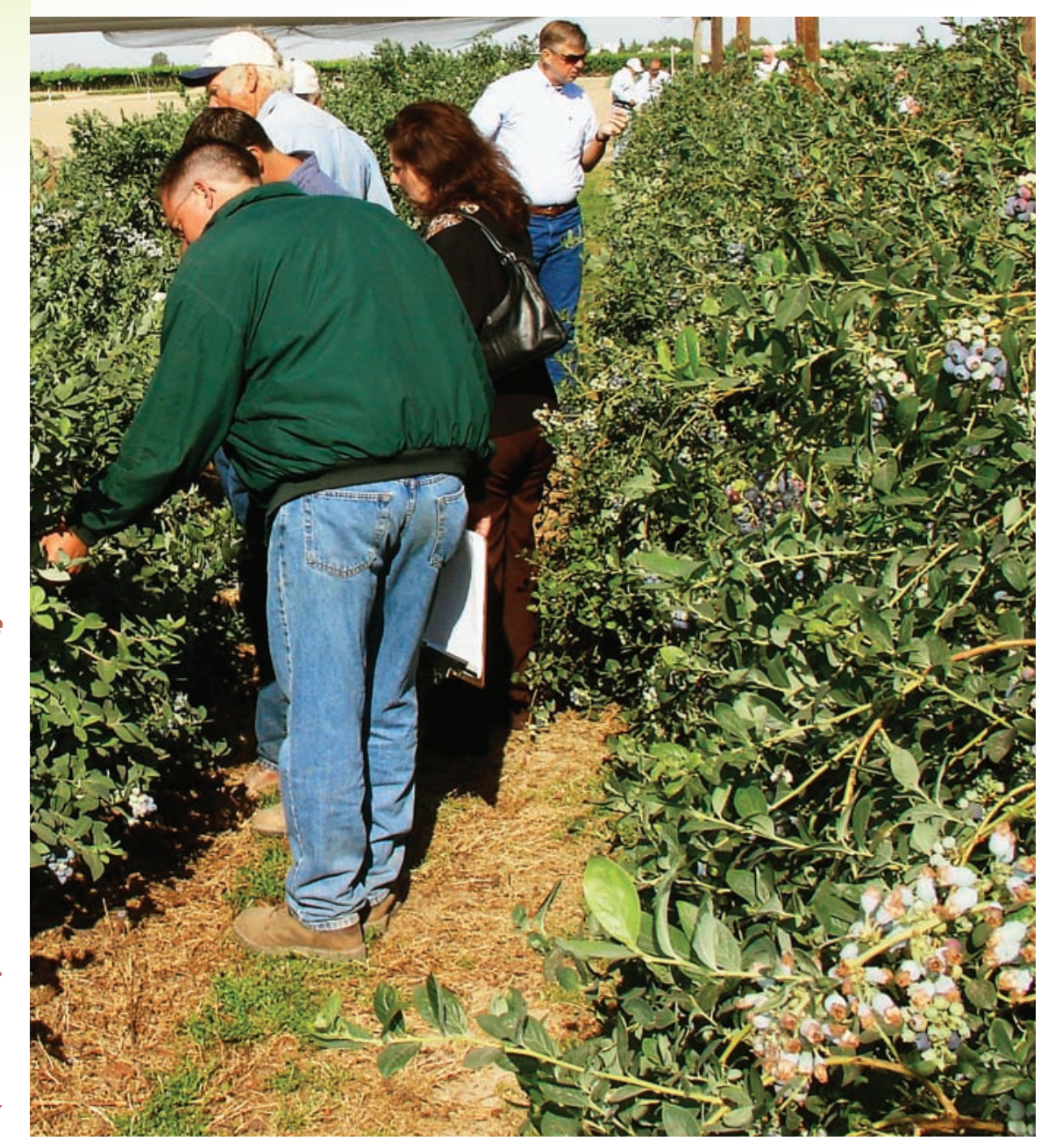

New blueberry cultivars that require fewer hours of chilling have made it possible to grow this specialty crop profitably in hot, dry places such as the San Joaquin Valley. Above, a blueberry field day at the UC Kearney Agricultural Center in Parlier.

Blueberry production in California was estimated in 2007 at around 4,500 acres (1,821 hectares) and is rapidly increasing. Common southern cultivars grown include 'Misty' and ' $\mathrm{O}$ 'Neal', but other improved southern highbush cultivars are now being grown from Fresno southward, such as 'Emerald', 'Jewel' and 'Star' (Hashim 2004). Southern highbush "low-chill" cultivars are notable for their productivity, fruit quality and adaptation (Draper 2007), and require only 150 to 600 chillhours, making them promising cultivars for the San Joaquin Valley's mild winters (600 to 1,200 chill-hours annually). Since 1998, we have conducted long-term productivity and performance evaluations of these cultivars at the University of California's Kearney
Agricultural Center in Parlier (Jimenez et al. 2005).

North American production of highbush blueberry has been increasing since 1975, due to expansion of harvested area and yields through improvements in cultivars and production systems. In 2005, North America represented $69 \%$ of the world's acreage of highbush blueberries, with 74,589 acres (30,185 hectares) producing 306.4 million pounds (139,000 metric tons). Acreage and production increased 11\% and $32 \%$, respectively, from 2003 to 2005. The U.S. West, South and Midwest experienced the highest increases in acreage. In 2005, $63 \%$ of the world's production of highbush blueberries went to the fresh market. North America accounts for a large part of global high- 


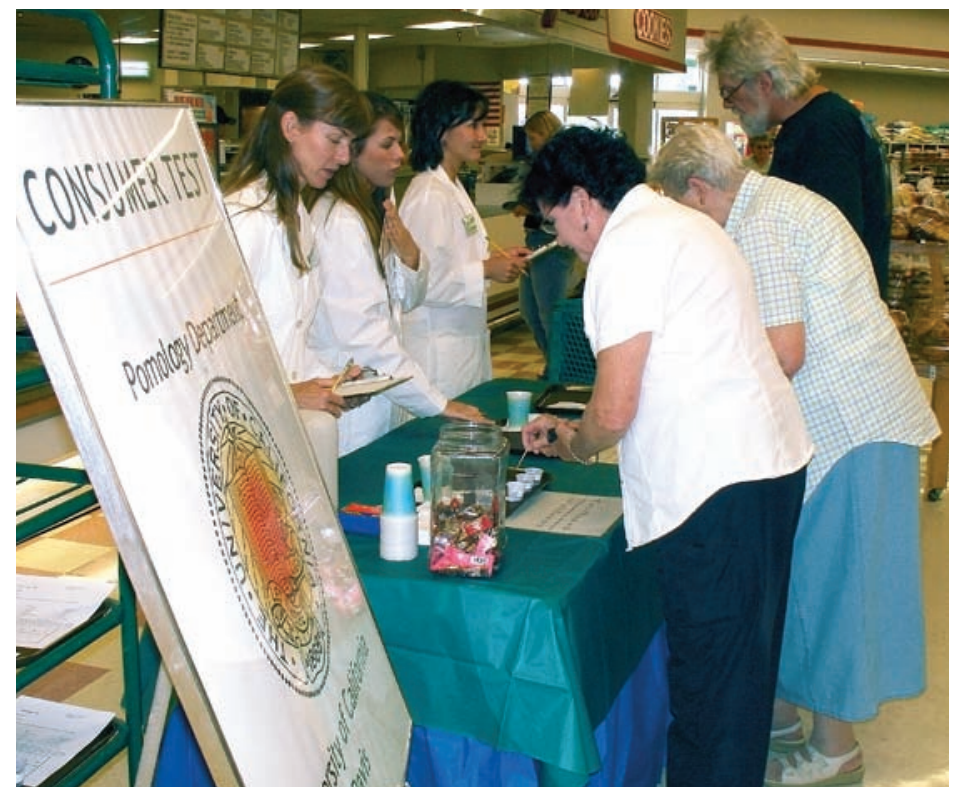

Consumers at a Fresno supermarket participated in taste tests of new southern highbush blueberry cultivars.

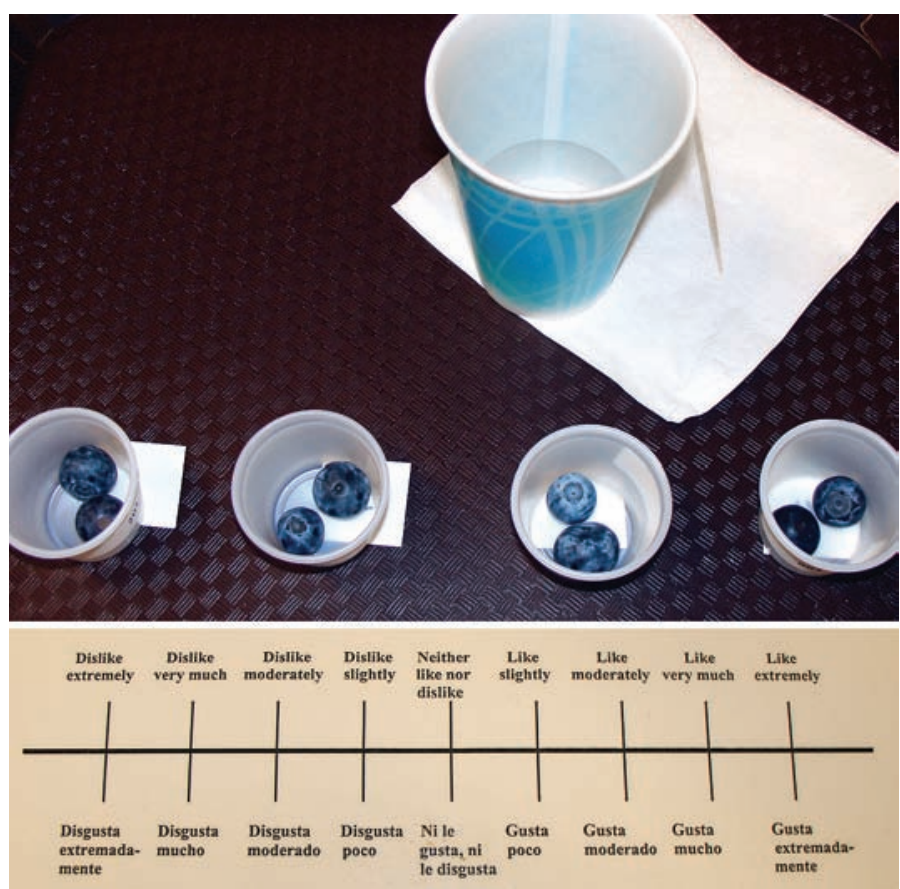

Blueberry samples were presented in random order for consumers to taste and rate on a 9-point hedonic scale (dislike extremely to like extremely). bush blueberry production, representing $67 \%$ of the fresh and $94 \%$ of the processed markets (Brazelton and Strik 2007).

Blueberry consumption is increasing, which is encouraging increased production. As a result, fresh blueberries are becoming a profitable specialty crop, especially in early production areas such as the San Joaquin Valley (Jimenez et al. 2005). In general, a consumer's first purchase is dictated by fruit appearance and firmness (texture). However, subsequent purchases are dependent on the consumer's satisfaction with flavor and quality, which are related to fruit soluble solids (mainly sugars), titratable acidity (organic acids), the ratio of soluble solids to titratable acidity, flesh firmness and antioxidant activity (Kader 1999).

Vaccinium species differ in chemical composition, such as sugars and organic acids. The sugars of the larger highbush blueberry cultivars that are grown in California are fructose, glucose and traces of sucrose. Lowbush blueberries (V. angustifolium) - which are wild, smaller and grow mostly in Maine lack sucrose. (Kalt and McDonald 1996). The composition of organic acids is a distinguishing characteristic among species. In highbush cultivars, the predominant organic acid is usually citric $(\sim 83 \%)$, while the percentages of succinic, malic and quinic acids are $11 \%$, $2 \%$ and $5 \%$, respectively. However, in "rabbiteye" blueberries ( $V$. ashei) the predominant organic acids are succinic and malic, with percentages of $50 \%$ and $34 \%$, respectively, while citric acid accounts for only about 10\% (Ehlenfeldt et al. 1994). These different proportions of organic acids affect sensory quality; the combination of citric and malic acids gives a sour taste, while succinic acid gives a bitter taste (Rubico and McDaniel 1992).

In addition to flavor, consumers also value the nutritional quality of fresh fruits and their content of energy, vitamins, minerals, dietary fiber and many bioactive compounds that are beneficial for human health (Kader 1999). Fruits, nuts and vegetables are of great importance for human nutrition, supplying vitamins, minerals and dietary fiber. For example, they provide $91 \%$ of vitamin C, $48 \%$ of vitamin A, $27 \%$ of vitamin B6, $17 \%$ of thiamine and $15 \%$ of niacin consumed in the United States (Kays 1997). The

\section{Fresh blueberries are becoming a profitable specialty crop, especially in early production areas such as the San Joaquin Valley.}



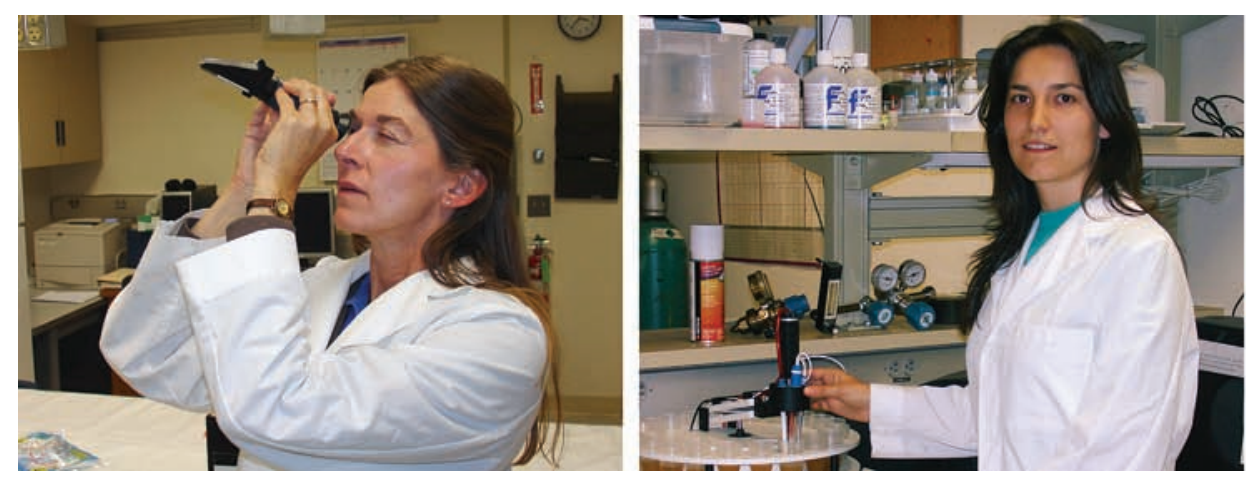

decided to evaluate fruit quality attributes, antioxidant capacity and consumer acceptance of the early-season blueberry cultivars currently being grown in California. We characterized the quality parameters (soluble solids concentration, titratable acidity, ratio of soluble solids to titratable acidity, firmness and antioxidant capacity) of six southern highbush blueberry cultivars grown in the San Joaquin Valley for three seasons (2005-2007), and evaluated their acceptance by consumers who eat fresh blueberries.

\section{Highbush blueberry evaluation}

Field plots. For the quality evaluations at UC Kearney Agricultural Center, we used three patented southern highbush blueberry cultivars - 'Emerald' (US Plant Patent 12165), 'Jewel' (US Plant Patent 11807) and 'Star' (US Plant Patent 10675), and three nonpatented cultivars - 'Reveille', 'O'Neal' and 'Misty'. The plants were started from tissue culture and then grown for two seasons by Fall Creek Farm and Nursery in Lowell, Ore. Before planting these cultivars in 2001, the trial plot was fumigated to kill nut grass (Cyperus rotundus and C. esculentus). Because blueberries require acidic conditions, the plot's soil was acidified with sulfuric acid, which was incorporated to a depth of 10 to 12 inches (25.4 to 30.5 centimeters) with flood irrigation, resulting in a $\mathrm{pH}$ ranging from 5.0 to 5.5. A complete (NPK) granular fertilizer (15-15-15) was broadcast-applied at a rate of 400 pounds per acre (448 kilograms per hectare).

The plants were mulched with 4 to 6 inches (10.2 to 15 centimeters) of pine mulch and irrigated with two drip lines on the surface of the mulch, one on each side of the plant row. Irrigation frequency was two to three times per week in the spring and daily during June and July. The emitter spacing was delivering 0.53 gallon (2 liters) per hour of water acidified with urea sulfuric acid fertilizer to a $\mathrm{pH}$ of 5.0.

The plot received an application of nitrogen in the first season, as well as in subsequent growing seasons. The trogen per acre at planting, 60 pounds (27.2 kilograms) the second year, 90 pounds (40.8 kilograms) the third year and 120 pounds (54.4 kilograms) the fourth year. Annual pest control was limited to one application of Pristine fungicide (a combination of the active ingredients pyraclostrobin and boscalid) in February for botrytis management, and two or three herbicide treatments of paraquat (Gramoxone). In year three, the plants received one insecticide treatement of spinosad (Success) for thrips management.

Twenty-eight plants per cultivar were planted in a randomized block design using seven plants per block (row) as an experimental unit, replicated in four rows. Rows were spaced 11 feet (3.4 meters) apart, with the plants in the rows spaced 3 feet $(0.9$ meter) apart, with a space of 4 feet (1.2 meters) between plots. Fruit was harvested at times when it would have been commercially viable if it had been in a commercial field. Fruit from each of the seven plant blocks was harvested and a composite sample of 80 random berries per each replication was used for quality evaluations.

Quality measurements. Berries were randomly selected from each replication for quality evaluation at the first harvest time for each respective season (2005-2007). During the 2007 season, in addition to the initial quality evalu18 inches (45.7 centimeters), with each rate was 80 pounds ( 36.3 kilograms) ni-

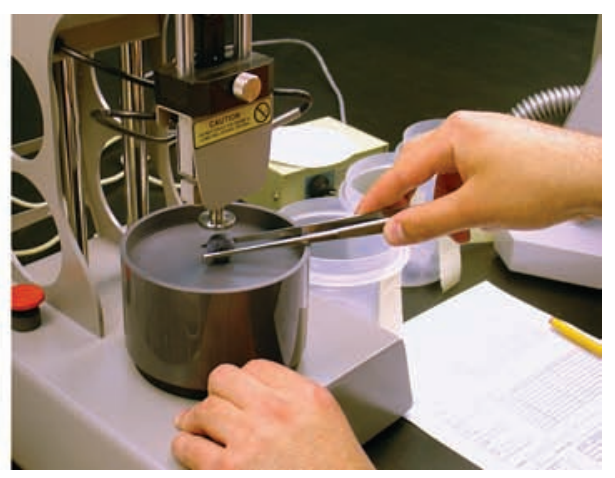

$\Delta$ After harvest, blueberries were tested for, left, soluble solids concentration (shown, Gayle Crisosto with refractometer), center, titratable acidity (shown, Vanessa Bremer with automatic titrator) and, right, firmness (shown, fruit texture analyzer), as well as other qualities.

ations, harvested berries were stored at $32^{\circ} \mathrm{F}\left(0^{\circ} \mathrm{C}\right)$ in plastic clam shells, and measured for firmness 15 days after harvest and for antioxidant capacity 5, 10 and 15 days after harvest. Three replications per cultivar (2005-2007 seasons) were measured for each quality parameter. The initial firmness of 10 individual berries per replication was measured with a Fruit Texture Analyzer (FTA) (Güss, GS.14, Strand, South Africa) (Slaughter and Rohrbach 1985). Each berry was compressed on the cheek with a 1-inch (2.5 centimeters) flat tip at a speed of 0.2 inch per second (5 millimeters) to a depth of 0.16 inch (4 millimeters) and the maximum value of force was expressed in pounds force (lbf) ( $1 \mathrm{lbf}=4.5$ Newtons).

Sixty berries per replication were then wrapped together in two layers of cheesecloth and squeezed with a hand press to obtain a composite juice sample. The juice was used to determine soluble solids concentration (SSC) with a temperature-compensated handheld refractometer (model ATC-1, Atago Co., Tokyo, Japan) and expressed as a percentage. Twenty-one hundredths of an ounce (6 grams) of the same juice sample was used to determine titratable acidity (TA) with an automatic titrator (TIM850 auto-titrator, Radiometer Analytical, Lyon, France) and reported as a percentage of citric acid. Some samples that had a high viscosity were centrifuged with a superspeed centri- 
fuge (SerVall type SS-1, U.S.A.) at 15,000 rpm for 5 minutes, in order to get liquid juice for soluble solids concentration and titratable acidity measurements (both methods were compared and no differences were observed [data not published]). The ratio of soluble solids concentration to titratable acidity was calculated.

Antioxidant analysis. Antioxidant capacity (Trolox Equivalent Antioxidant Capacity [TEAC]) was measured in the 2005 and 2007 seasons. Eighteenhundredths of an ounce (5 grams) of berries (not used for quality measurements) per replication was used to determine the level of antioxidants by the DPPH free-radical method (BrandWilliams et al. 1995). Samples were extracted in methanol to assure a good phenolic representation, homogenized using a polytron (Ultra-Turrax TP 18/101 S1, Junke \& Kunkel, Staufen, Germany) and centrifuged (Sorvall

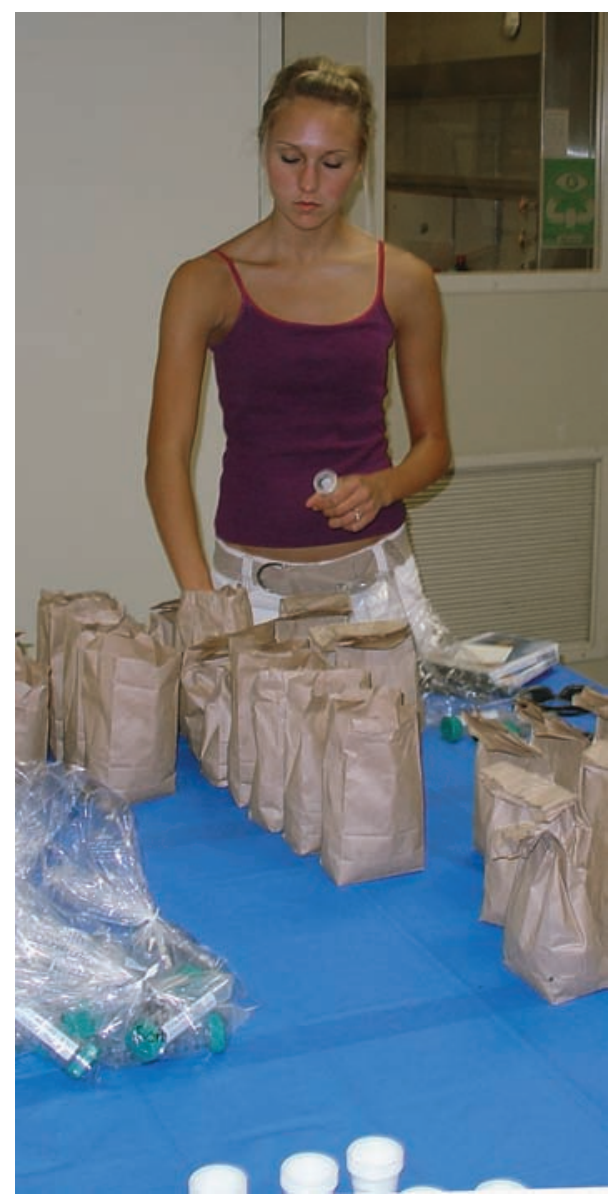

Lab assistant Megan Bishop prepares blueberry samples for antioxidant analysis.
RC5C, Du Pont Company, Wilmington, Del.) for 25 minutes. The supernatant was analyzed against the standard, Trolox, a water-soluble vitamin E analogue, and reported in micromoles Trolox equivalents per gram of fresh tissue ( $\mu$ moles TE/g FW).

Consumer tests. An in-store consumer test was conducted on 'Jewel', 'O'Neal' and 'Star' blueberry cultivars in 2006, and on the six blueberry cultivars studied in 2007, using methods described previously (Crisosto and Crisosto 2001). The fruit samples were held for 2 days after harvest at $32^{\circ} \mathrm{F}\left(0^{\circ} \mathrm{C}\right)$ prior to tasting. One hundred consumers who eat fresh blueberries, representing a diverse combination of ages, ethnic groups and genders, were surveyed in a major supermarket in Fresno County.

Each consumer was presented with a sample of each blueberry cultivar in random order at room temperature, $68^{\circ} \mathrm{F}\left(20^{\circ} \mathrm{C}\right)$. A sample consisted of three fresh whole blueberries presented in a 1-ounce (30 milliliters) soufflé cup labeled with a three-digit code. At the supermarket, the samples were prepared in the produce room out of sight from the testing area. For each sample, the consumer was asked to taste it, and then asked to indicate which statement best described how they felt about the sample on a 9-point hedonic scale (dislike extremely to like extremely). Consumers were instructed to sip bottled water between samples to cleanse their palates. Consumer acceptance was measured as both degree of liking (on a scale of 1 to 9) and percentage acceptance, which was calculated as the number of consumers liking the sample (score $>5.0$ ) divided by the total number of consumers within that sample (Lawless and Heymann 1998). In a similar manner, the percentage of consumers disliking (score < 5.0) and neither liking nor disliking (score $=5.0$ ) the sample was calculated.

Statistical analysis. Quality values (firmness, SSC, TA, SSC:TA and TEAC) and data on degree of liking were analyzed with analysis of variance (multifactor ANOVA) and LSD mean separation $(P \leq 0.05)$ with the SAS program.
TABLE 1. Production of six southern highbush blueberry cultivars (2005-2007)*

\begin{tabular}{lccc}
\hline \hline Cultivar & $\mathbf{2 0 0 5}$ & 2006 & 2007 \\
\hline Emerald & 10,747 & 18,494 & 19,623 \\
Jewel & 8,411 & 26,966 & 23,228 \\
Star & 3,821 & 9,968 & 17,198 \\
Reveille & 7,081 & 7,039 & 8,313 \\
O'Neal & 3,830 & 7,232 & 9,708 \\
Misty & 7,375 & 8,128 & 11,157 \\
* Yield was calculated from 21 feet of row including seven \\
plants spaced 3 feet apart.
\end{tabular}

\section{Blueberry cultivar performance}

Production. Among the studied cultivars, 'Emerald' and 'Jewel' had the highest productivity for 2005 to 2007 (table 1). However, 'Star' had an unexpectedly high productivity in 2007. Yield increases for all varieties were due to the maturity of the plants. At planting, the tissue-culture plants were 2 years old; as they matured, they all produced larger yields. The harvest period for 'Star' began the first week of May and ended after the third harvest. Most other cultivars required five or more harvests, 1 week apart. Based on the berry size (table 2), the cultivars studied would be separated into large berry ('Emerald', 'Jewel' and 'Star') and medium berry ('Reveille', 'O'Neal' and 'Misty'). The cultivars studied have an erect plant stature, except for 'Misty', which has a spreading stature that makes hand-harvest difficult.

Fruit quality. Quality attributes such as soluble solids concentration, titratable acidity, soluble-solids-totitratable-acidity ratio and firmness were significantly different among cultivars and seasons (table 3). There was wide variability in soluble solids concentration among cultivars. 'Reveille' had the highest average value $(14.4 \%)$ of the 2005 to 2007 seasons, followed by 'Misty' (12.3\%), 'Emerald' (12\%) and 'Star' (11.9\%). 'Jewel' (11.7\%) and 'O'Neal' (11.4\%) had the lowest soluble solids concentration within this group.

Titratable acidity within cultivars was less variable, and only ' $\mathrm{O}$ 'Neal' had a significantly lower average value $(0.54 \%)$ than the rest of the tested cultivars. Titratable acidity varied from $0.70 \%$ to $0.80 \%$ within this group with the exception of 'O'Neal'. Cultivars segregated into three groups based on their soluble-solids-to-titratable-acidity 
ratio. Because of its low titratable acidity, 'O'Neal' had the highest ratio, while 'Jewel' had the lowest ratio due to its high titratable acidity. The rest of the cultivars formed an intermediate group in which the soluble-solids-to-titratableacidity ratio ranged from 17 to 20.3 . 'Jewel' and 'O'Neal' also had the lowest firmness (1.2 lbf), while 'Reveille' and 'Misty' had the highest (1.6 lbf). 'Emerald' and 'Star' were significantly different than these two groups, forming an intermediate group (1.5 lbf).

Quality attributes were also significantly affected by the season. Soluble solids concentration across all cultivars was highest in 2007 and lowest in 2006, while titratable acidity was highest in 2006. Soluble-solids-to-titratableacidity ratio and firmness were significantly higher in 2007 than the other years. There was a significant interaction between cultivar and season for all these quality attributes (table 3).

The lowest soluble solids concentration was 10.8\% in 2006 for 'O'Neal' and the highest was $15.8 \%$ for 'Reveille' in 2007. During this 3-year period, all of the cultivars yielded soluble solids concentrations higher than $10 \%$, which has been proposed as a minimum quality index for blueberries (Kader 1999). Titratable acidity was similar among cultivars in these three seasons except for ' $\mathrm{O}$ ' $\mathrm{Neal}^{\prime}$ in 2007, which reached $0.3 \%$, and 'Jewel' and 'Emerald' in 2006 with about 1.0\%. 'O'Neal' (40.5) and 'Reveille' (22.9) had the highest soluble-solids-to-titratableacidity ratio, followed by the rest of the cultivars with ratios from 11.4 to 20.6. During this 3-year period, 'Jewel' and 'O'Neal' were the softest cultivars, and 'Misty' and 'Reveille' the firmest.

Antioxidant capacity was significantly different among the cultivars but not between seasons (table 3). There was a wide variability of TEAC within cultivars. 'Misty' had the highest average TEAC (19.6 $\mu \mathrm{mol} \mathrm{TE} / \mathrm{g}$ FW) followed by 'Reveille' (17.3) and 'Emerald' (16.1). 'Star' (12.4), 'O'Neal' (12.6) and 'Jewel' (11.0) had the lowest TEAC within this group. Like the rest of the quality attributes, there was a significant interaction between cultivars and seasons for antioxidant
TABLE 2. Characteristics of six southern highbush blueberry cultivars

\begin{tabular}{|c|c|c|c|c|c|}
\hline Cultivar & Plant stature & Harvest period* & Fruit sizet & Berry grade $¥$ & Hand-harvest ease \\
\hline Emerald & Erect & Early/midseason & $50-80$ & Large & Moderately easy \\
\hline Jewel & Erect & Early & $60-100$ & Large & Moderately easy \\
\hline Star & Erect & Early & $60-70$ & Large & Very easy \\
\hline Reveille & Very erect & Early & $100-130$ & Medium & Moderate \\
\hline O’Neal & Erect & Early & $100-130$ & Medium & Easy \\
\hline Misty & Spreading & Early/midseason & $80-130$ & Medium & Difficult \\
\hline \multicolumn{6}{|c|}{$\begin{array}{l}\text { * Harvest period specifies initiation of harvest. Early = initial harvest; early/midseason = } 7 \text { days later } \\
\text { † Number of berries per } 6 \text { oz. ( } 0.18 \text { liter) cup. } \\
\text { \# Based on average fruit size: extra large, < } 64 \text { berries/cup ( } 6 \text { oz.); large, } 64-91 \text { berries/cup ( } 6 \text { oz.); } \\
\text { medium, } 92-134 \text { berries/cup ( } 6 \text { oz.). } \\
\text { Source: Jimenez et al. } 2005 \text {. }\end{array}$} \\
\hline
\end{tabular}

\begin{tabular}{|c|c|c|c|c|c|}
\hline Cultivar & SSC * & TA $t$ & SSC:TA & Firmness & TEAC § \\
\hline & $\%$ & $\%$ citric acid & ratio & Ibf & $(\mu \mathrm{mol} T \mathrm{TE} / \mathrm{g} F W)$ \\
\hline \multicolumn{6}{|l|}{2005} \\
\hline Emerald & 12.1 cdef ๆ & $0.63 \mathrm{ab}$ & $18.4 \mathrm{~b}$ & $1.60 \mathrm{ab}$ & $19.1 \mathrm{ab}$ \\
\hline Jewel & 11.9 cdef & $0.67 \mathrm{ab}$ & $18.1 \mathrm{~b}$ & $1.07 \mathrm{~d}$ & $10.3 \mathrm{~d}$ \\
\hline Misty & $12.2 \mathrm{cdef}$ & $0.70 a b$ & $16.6 \mathrm{~b}$ & $1.57 \mathrm{ab}$ & $21.9 a$ \\
\hline O'Neal & 11.8 def & $0.60 \mathrm{ab}$ & $19.0 \mathrm{~b}$ & $1.30 \mathrm{bcd}$ & $13.6 \mathrm{~cd}$ \\
\hline Reveille & $14.3 \mathrm{ab}$ & $0.80 a$ & $18.1 \mathrm{~b}$ & $1.40 \mathrm{bcd}$ & $13.8 \mathrm{~cd}$ \\
\hline Star & 12.9 bcde & $0.77 \mathrm{a}$ & $16.4 \mathrm{~b}$ & $1.57 \mathrm{ab}$ & $12.1 \mathrm{~d}$ \\
\hline \multicolumn{6}{|l|}{2006} \\
\hline Emerald & $11.6 \mathrm{def}$ & $0.90 \mathrm{a}$ & $13.2 \mathrm{~b}$ & $1.43 \mathrm{bcd}$ & N/A \\
\hline Jewel & 10.9 ef & $1.00 \mathrm{a}$ & $11.4 \mathrm{~b}$ & $1.13 \mathrm{~cd}$ & N/A \\
\hline Misty & 11.1 ef & $0.57 \mathrm{ab}$ & $20.6 \mathrm{~b}$ & $1.37 \mathrm{bcd}$ & N/A \\
\hline O’Neal & $10.8 \mathrm{f}$ & 0.77 a & $14.5 \mathrm{~b}$ & $1.13 \mathrm{~cd}$ & N/A \\
\hline Reveille & $13.3 \mathrm{bdf}$ & $0.70 \mathrm{ab}$ & $20.0 \mathrm{~b}$ & $1.57 \mathrm{ab}$ & N/A \\
\hline Star & $11.1 \mathrm{ef}$ & $0.70 a b$ & $17.4 \mathrm{~b}$ & $1.50 \mathrm{abc}$ & N/A \\
\hline \multicolumn{6}{|l|}{2007} \\
\hline Emerald & $12.3 \mathrm{cdef}$ & $0.60 a b$ & $20.0 \mathrm{~b}$ & $1.60 \mathrm{ab}$ & $13.2 \mathrm{~cd}$ \\
\hline Jewel & $12.3 \mathrm{cdef}$ & $0.73 a b$ & $17.2 \mathrm{~b}$ & $1.30 \mathrm{bcd}$ & $11.7 \mathrm{~d}$ \\
\hline Misty & $13.7 \mathrm{bc}$ & $0.83 a$ & $17.3 \mathrm{~b}$ & $1.87 \mathrm{a}$ & $17.4 \mathrm{bc}$ \\
\hline O’Neal & 11.5 def & $0.27 \mathrm{~b}$ & $40.5 \mathrm{a}$ & $1.27 \mathrm{bcd}$ & $11.7 \mathrm{~d}$ \\
\hline Reveille & $15.8 \mathrm{a}$ & $0.70 a b$ & $22.9 \mathrm{ab}$ & $1.90 \mathrm{a}$ & $20.7 a b$ \\
\hline Star & 11.6 def & $0.67 \mathrm{ab}$ & $17.1 \mathrm{~b}$ & $1.50 \mathrm{abc}$ & $12.7 \mathrm{~d}$ \\
\hline LSD 0.05 & 1.88 & 0.48 & 18.07 & 0.41 & 4.4 \\
\hline$P$ value & 0.001 & 0.001 & $<0.0001$ & $<0.0001$ & 0.0042 \\
\hline \multicolumn{6}{|c|}{$\begin{array}{l}\text { * Soluble solids concentration. } \\
\text { † Titratable acidity. } \\
\text { \# Firmness represents the maximum value of force expressed in pounds force (lbf) ( } 1 \mathrm{lbf}=4.5 \text { Newtons) } \\
\text { required to compress the fruit } 0.16 \text { inches }(4 \mathrm{~mm}) \text { using a fruit texture analyzer with a } 1 \text {-inch ( } 2.5 \text {-centimeters) } \\
\text { flat tip at a speed of } 0.2 \mathrm{inch} / \mathrm{sec}(5 \mathrm{~mm} / \mathrm{sec}) \text {. }\end{array}$} \\
\hline \multicolumn{6}{|c|}{ § TEAC (Trolox Equivalent Antioxidant Capacity). } \\
\hline
\end{tabular}

TABLE 4. Acceptance of six southern highbush blueberry cultivars by U.S. consumers in consumer test during 2007 season

\begin{tabular}{|c|c|c|c|c|}
\hline Cultivar & Degree of liking* & Acceptance & Neither like nor dislike & Dislike \\
\hline & $1-9$ & $\ldots \ldots \ldots \ldots$ & $\ldots \ldots \ldots \% \ldots \ldots$ & $\ldots \ldots$ \\
\hline Emerald & $6.2 \mathrm{cdt}$ & 72.3 & 11.9 & 15.8 \\
\hline Jewel & $6.7 \mathrm{~b}$ & 82.2 & 4.9 & 12.9 \\
\hline Misty & $6.9 \mathrm{~b}$ & 84.2 & 6.9 & 8.9 \\
\hline O'Neal & $5.9 \mathrm{~d}$ & 67.3 & 12.9 & 19.8 \\
\hline Reveille & $7.4 \mathrm{a}$ & 92.1 & 2.0 & 5.9 \\
\hline Star & $6.6 \mathrm{bc}$ & 80.2 & 8.9 & 10.9 \\
\hline LSD 0.05 & 0.44 & - & - & - \\
\hline$P$ value & $<0.0001$ & & & \\
\hline \multicolumn{5}{|c|}{$\begin{array}{l}\text { * Degree of liking: } 1=\text { dislike extremely, } 2=\text { dislike very much, } 3=\text { dislike moderately, } 4=\text { dislike slightly, } \\
5=\text { neither like nor dislike, } 6=\text { like slightly, } 7=\text { like moderately, } 8=\text { like very much, } 9=\text { like extremely. }\end{array}$} \\
\hline
\end{tabular}


capacity (data not shown). Storage of the six blueberry cultivars at $32^{\circ} \mathrm{F}\left(0^{\circ} \mathrm{C}\right)$ for 15 days did not affect either antioxidant capacity or firmness, except for 'O'Neal' and 'Misty', whose firmness was reduced slightly but not significantly (data not shown).

Consumer acceptance. During the 2006 season, our in-store test results indicated that consumers liked the three tested cultivars slightly to moderately, with an acceptance range of $73.3 \%$ to $80 \%$. There were no significant differences in degree of liking between 'Jewel', 'O'Neal' and 'Star'. In these three cultivars the percentage of consumers disliking these fruit reached about $17 \%$ (data not shown).

During the 2007 season, there were significant differences in degree of liking between the six cultivars tested (table 4). In this test, degree of liking varied from liking slightly to moderately. 'Reveille' had the highest (7.4) and 'O'Neal' the lowest (5.9) degree of liking with an acceptance of $92.1 \%$ and $67.3 \%$, respectively. Degree of liking of 'Misty' and 'Jewel' was significantly lower than 'Reveille', but higher than 'Star' and 'Emerald'. Acceptance was near $80 \%$ for 'Jewel', 'Misty' and 'Star', while only $67 \%$ for 'O'Neal' and $72 \%$ for 'Emerald'. The percentage of consumers that disliked these cultivars varied from 5.9\% to $19.8 \%$; 'Reveille' and 'Misty' had the lowest dislike percentage and ' $\mathrm{O}$ ' $\mathrm{Neal}^{\prime}$ the highest.

Degree of liking for 'Jewel' and 'Star' were similar (from slight to moderate) during the two seasons. For 'O'Neal', the degree of liking decreased from like slightly-moderately to like slightly. This reduction in consumer acceptance can be explained by the change of titratable acidity from $0.6 \%$ to $0.8 \%$ in previous years down to $0.3 \%$ in 2007 that only occurred in ' $\mathrm{O}$ ' Neal'. This reduction of titratable acidity for ' $\mathrm{O}$ 'Neil' was independent of soluble solids concentration, which remained between $10.8 \%$ and $11.8 \%$ for the 2005 to 2007 seasons.

These results indicated that blueberries with very low titratable acidity $(0.3 \%)$, despite soluble solids concentrations between $10 \%$ and $12 \%$, are not acceptable to consumers. A similar situation has been observed in white and yellow flesh peaches and nectarines with very low acidity (less than $0.4 \%$ ) (C. and G. Crisosto, personal communication). This reduction in consumer acceptance also points out that the ratio of soluble solids to titratable acidity is not a good indicator for blueberry taste when titratable acidity is low. We are not sure of the reasons for the low titratable acidity in 2007 of 'O'Neal' fruit, which appears to be independent of other cultivars. The 2007 season was characterized by high chilling accumulation and a hotter than normal spring, which could have affected ' $\mathrm{O}$ 'Neal' ripening.

\section{Choosing a variety}

The six southern highbush blueberry cultivars studied ('Emerald', 'Jewel', 'Star', 'Reveille', 'O'Neal' and 'Misty') growing in the San Joaquin Valley had soluble solids concentration levels above the $10 \%$ proposed for a minimum quality standard. Titratable acidity ranged from $0.6 \%$ to $0.9 \%$, with the exception of $0.3 \%$ (2007) for 'O'Neal'. Firmness ranged from 1.2 to 1.6 lbf. 'Reveille' was the cultivar with the highest soluble solids concentration, firmness and degree of liking. Antioxidant capacity ranged from 10

\section{References}

Brand-Williams W, Cuvelier ME, Berset C. 1995. Use of a free radical method to evaluate antioxidant activity. Lebensmittel Wissenschaft Technologie 28:25-30.

Brazelton D, Strik BC. 2007. Perspective on the U.S. and global blueberry industry. J Am Pom Soc 61(3):144-7.

Crisosto CH, Crisosto GM. 2001. Understanding consumer acceptance of early harvested 'Hayward' kiwifruit. Postharvest Biol Technol 22:205-13.

Draper A. 2007. Blueberry breeding: Improving the unwild blueberry. J Am Pom Soc 61(3):140-3.

Ehlenfeldt MK, Meredith FI, Ballington JR. 1994. Unique organic profile of rabbiteye vs. highbush blueberries. HortScience 29(4):321-3.

Hashim J. 2004. Blueberry production gaining in California. Western Farm Press. http://westernfarmpress. com/mag/farming_blueberry_production_gaining.

Jimenez M, Carpenter F, Molinar RH, et al. 2005. Blueberry research launches exciting new California specialty crop. Cal Ag 59(2):65-9.

Kader AA. 1999. Fruit maturity, ripening, and quality relationship. Acta Horticulturae (ISHS) 485:203-8. to $22 \mu$ moles TE/g FW, with 'Misty' and 'Reveille' the cultivars with higher antioxidant capacity for the 2005 and 2007 seasons. Antioxidant capacity and firmness of the cultivars studied was not affected by storage up to 15 days at $32^{\circ} \mathrm{F}\left(0^{\circ} \mathrm{C}\right)$. Blueberries with very low titratable acidity, despite acceptable soluble solids concentration, had lower consumer acceptance and degree of liking, indicating that the solublesolids-to-titratable-acidity ratio is not a good indicator of consumer acceptance for blueberries.

For San Joaquin Valley conditions, these cultivars are all good options for our fast-growing, early fresh blueberry market.

V. Bremer is Research Assistant, G. Crisosto is Associate Specialist, S. Dollahite is Research Assistant, and C.H. Crisosto is Postharvest Physiologist, Department of Plant Sciences, UC Davis, located at the UC Kearney Agricultural Center; and R. Molinar and M. Jimenez are Farm Advisors, UC Cooperative Extension, Fresno and Tulare counties, respectively. Thanks to the UC Small Farm Center and Kearney Agricultural Center for their support on the development of this work.

Kalt W, McDonald JE. 1996. Chemical composition of lowbush blueberry cultivars. J Am Soc Hort Sci 121(1):142-6.

Kays SJ. 1997. Postharvest Physiology of Perishables Plant Products. Athens, GA: Exon Pr. 532 p.

Lawless HT, Heymann H. 1998. Sensory Evaluation of Food: Principles and Practices. Food Science Texts Series. NY: Chapman Hall. 827 p.

Rubico SM, McDaniel MR. 1992. Sensory evaluation of acids by free-choice profiling. Chemical Senses 17(3):273-89.

Schotsmans W, Molan A, MacKay B. 2007. Controlled atmosphere storage of rabbiteye blueberries enhances postharvest quality aspects. Postharvest Biol Technol 44:277-85.

Shukitt-Hale B, Carey AN, Jenkins D, et al. 2007. Beneficial effects of fruit extracts on neuronal function and behavior in a rodent model of accelerated aging. Neurobiol Aging 28(8):1187-94.

Slaughter DC, Rohrbach RP. 1985. Developing a blueberry firmness standard. Trans Am Soc Agric Eng 28(3):986-92.

Strik B, Yarborough D. 2005. Blueberry production trends in North America, 1992 to 2003 and predictions for growth. HortTechnol 15:391-8. 